\begin{tabular}{|c|c|c|c|}
\hline \multirow[t]{2}{*}{$\begin{array}{l}\text { Clinical } \\
\text { characteristic }\end{array}$} & \multirow[t]{2}{*}{ Variable } & \multicolumn{2}{|c|}{$\begin{array}{l}\text { Patients with this characteristic, } n \\
(\%)\end{array}$} \\
\hline & & $\begin{array}{l}\text { At or within } 1 \text { year } \\
\text { after diagnosis } \\
(\mathrm{n}=17,244)\end{array}$ & $\begin{array}{l}\text { At any time } \\
(n=17,244)\end{array}$ \\
\hline \multirow[t]{14}{*}{ Comorbidities } & Ischaemic heart disease & $3638(21.1)$ & $4338(25.2)$ \\
\hline & Other infections of airways & $2664(15.4)$ & $6960(40.4)$ \\
\hline & Acid-related disorders & $2394(13.9)$ & $3056(17.7)$ \\
\hline & COPD & $2249(13.0)$ & $2845(16.5)$ \\
\hline & Angina & $2233(12.9)$ & $2539(14.7)$ \\
\hline & Diabetes (types 1 and 2) & $1471(8.5)$ & $1901(11.0)$ \\
\hline & Bacterial pneumonia & $998(5.8)$ & $2954(17.1)$ \\
\hline & Myocardial infarction & $612(3.5)$ & $2408(14.0)$ \\
\hline & Sleep apnoea & $514(3.0)$ & $665(3.9)$ \\
\hline & Depression & $429(2.5)$ & $547(3.2)$ \\
\hline & Anxiety & $329(1.9)$ & $450(2.6)$ \\
\hline & Pulmonary hypertension & $303(1.8)$ & $447(2.6)$ \\
\hline & Bronchitis & $280(1.6)$ & $1146(6.6)$ \\
\hline & Peripheral vascular disease & $259(1.5)$ & $313(1.8)$ \\
\hline \multirow{9}{*}{$\begin{array}{l}\text { Concomitant } \\
\text { medications }\end{array}$} & Cardiovascular medication & $7965(46.2)$ & 11852 \\
\hline & & & $(68.7)$ \\
\hline & $\begin{array}{l}\text { Anti-coagulants/anti- } \\
\text { thrombotics }\end{array}$ & $6569(38.1)$ & $\begin{array}{l}10493 \\
(60.9)\end{array}$ \\
\hline & Corticosteroids for systemic use & $6086(35.3)$ & $\begin{array}{l}10307 \\
(59.8)\end{array}$ \\
\hline & $\begin{array}{l}\text { Acid-related disorders } \\
\text { medication }\end{array}$ & $5889(34.2)$ & $\begin{array}{l}10183 \\
(59.1)\end{array}$ \\
\hline & Heart failure medication & $5224(30.3)$ & $9250(53.6)$ \\
\hline & $\begin{array}{l}\text { Cholesterol-lowering } \\
\text { medication }\end{array}$ & $3653(21.2)$ & $6451(37.4)$ \\
\hline & $\begin{array}{l}\text { Anti-neoplastic and } \\
\text { immunomodulating agents }\end{array}$ & $1793(10.4)$ & $3688(21.4)$ \\
\hline & Oxygen & $1218(7.1)$ & $2447(14.2)$ \\
\hline
\end{tabular}

Conclusions Analysis of the first national cohort of patients with pulmonary fibrosis in Sweden has found slightly higher incidence rates of IPF than those of previous studies, though this may be due to identification of patients with IPF using ICD-10 code J84.1 ('other interstitial pulmonary diseases with fibrosis'). Though a diagnosis algorithm was used to refine the population for those with IPF, these criteria might not exclude all patients with non-IPF interstitial lung diseases. The frequencies of clinical characteristics in this population were broadly in line with those previously observed in patient populations with IPF.

\section{P150 NECK AS MEDIASTINAL EXTENSION: DIAGNOSIS OF SARCOIDOSIS BY CORE BIOPSY OF CERVICAL LYMPH NODES}

A Fahim, MM Qasim, D Rosewarne. New Cross Hospital, Wolverhampton, UK

\subsection{6/thoraxjnl-2017-210983.292}

Background Sarcoidosis is a multi-system granulomatous disease of uncertain aetiology. It is characterised by bilateral hilar lymphadenopathy. The diagnosis is best supported by the histological evidence of non-caseating granulomas in the affected organ (s). The diagnostic procedures for histological confirmation are invasive and a less invasive approach to diagnostic pathway is warranted.

Objectives The utility of diagnostic value of neck ultrasound was retrospectively evaluated in this study. A histological diagnosis was made by ultrasound guided head and neck core biopsy to confirm clinically and radiologically suspected sarcoidosis.

Methods Following clinical assessment by a respiratory physician, 25 patients were referred for sonographic evaluation of the head and neck by a thoracic radiologist after CT scan in an attempt to avoid the use of more invasive and expensive tests such as endobronchial ultrasound (EBUS) and mediastinoscopy. Typically these patients had obvious mediastinal adenopathy +/-parenchymal lung disease, but not clinically apparent neck nodes. Where no cervical lymph node suitable for biopsy was seen, the parotid glands were evaluated and biopsied if deemed abnormal. Patients with no suitable lymph nodes and normal parotid glands were returned for consideration of other diagnostic techniques.

Results A diagnosis of sarcoidosis was made in all cases where a core biopsy of cervical lymph nodes (figure 1) was attempted ( 23 out of 25 patients). It is emphasised that the cervical lymph nodes in this series were not particularly enlarged, short axis dimensions being under $10 \mathrm{~mm}$ in the majority of cases biopsied, and that these sub-centimetre short axis lymph nodes did not have any specific sonographic appearances to mark them as pathological. Nevertheless histological examination revealed non-caseating granulomas in all cases. In a further two cases, where no neck nodes were seen, a histological diagnosis of sarcoidosis was made from biopsy of diffusely abnormal parotid gland tissue.

Conclusions Given the clear advantages of cervical diagnosis in terms of invasiveness and economy compared to mediastinal alternatives, it is suggested that where the expertise for core biopsy of normal sized cervical lymph nodes is readily available, the technique may be considered as a first line investigation for the diagnosis of sarcoidosis.

\section{P151 THE ROLE OF BRONCHOALVEOLAR LAVAGE AND ITS QUALITY IN THE DIAGNOSIS OF INTERSTITIAL LUNG DISEASE}

A Ebraheem, L Macfarlane, R Booton, N Chaudhuri. University Hospital Of South Manchester NHS Foundation Trust, Manchester, UK

\subsection{6/thoraxjnl-2017-210983.293}

Background Bronchoalveolar lavage (BAL) is a widely used diagnostic tool for suspected Interstitial Lung Disease (ILD) patients and is advocated in ILD guidelines. ${ }^{1}$ We aimed to evaluate the quality of BAL sampling in the diagnosis of ILD compared to BAL guidelines. $^{2}$

Methods Retrospective cohort study of all BALs performed in ILD at the University Hospital of South Manchester (UHSM) between January 2015 and November 2016. Electronic reports and histopathological cellular analysis were assessed for qualitative outcomes as per BAL guidelines. ${ }^{2}$

Results 416 patients' coded as BAL sampling. 95 (24\%) were performed in the diagnostic strategy for ILD. The mean age was 58.9 (range 18-89). 36 (37.9\%) were Female and 59 $(62.1 \%)$ were male.13 (13.7\%) had lymphocyte count $\geq 15 \%$, 
and $4(4.2 \%)$ had a percentage $\geq 50 \%$. Eosinophil count was $\geq 5 \%$ in $17(17.9 \%)$, and $\geq 25 \%$ in 2 (2.1\%). When assessing quality of samples as per guidelines the percentage of other cells (epithelial/columnar cells) at analysis was more than $5 \%$ in $57(60 \%)$ patients. In 37 (38.9\%) patients the volume instilled was more than $100 \mathrm{ml}$. In only $13(13.7 \%)$ patients the volume of fluid retained back was $\geq 30 \%$ of instilled volume. Despite this $76(80 \%)$ patients the volume of fluid obtained for analysis was more than $10 \mathrm{ml}$. There were no immediate complications reported. 50 (52.6\%) of the operators were consultants, $30(31.6 \%)$ were registrars, and in 15 $(15.8 \%)$ operator was not recorded.

Conclusion The quality of BAL sample is very important for diagnostic accuracy in ILD. Our data shows that BAL performed by general respiratory physicians can be of poor quality. We would advocate adequate training in BAL plus investment in dedicated ILD lists may improve engagement and quality. This data supports the BTS bronchoscopy guidelines in performing regular audit to ensure quality is maintained.

\section{REFERENCE}

1. Wells A, Hirani N. Interstitial lung disease guideline. Thorax 2008;63(5):v1-v58. 2. Meyer K, Raghu G, Baughman R, et al. An Official American thoracic society clinical practice guideline: The clinical utility of bronchoalveolar lavage cellular analysis in interstitial lung disease. American Journal of Respiratory and Critical Care Medicine 2012;185(9):1004-1014

\section{P152 THE ASSOCIATION BETWEEN ADULT HEIGHT, SOCIOECONOMIC STATUS AND IDIOPATHIC PULMONARY FIBROSIS: A POPULATION BASED CASE- CONTROL STUDY}

${ }^{1} \mathrm{~T}$ Glover, ${ }^{2} \mathrm{JP}$ Hutchinson, ${ }^{2} \mathrm{~T}$ McKeever, ${ }^{2} \mathrm{RB}$ Hubbard, ${ }^{2} \mathrm{~V}$ Navaratnam. ${ }^{1}$ Nottingham University Medical School, University of Nottingham, Nottingham, UK; ${ }^{2}$ Division of Epidemiology and Public Health, University of Nottingham, Nottingham, UK

\subsection{6/thoraxjnl-2017-210983.294}

Background Idiopathic pulmonary fibrosis (IPF) is an increasingly important public health issue worldwide, but the underlying aetiology is still unknown. The aim of this study was to investigate whether adult height or socioeconomic status are associated with the lifetime risk of developing IPF.

Methods We used data from The Health Improvement Network (THIN), an electronic longitudinal UK primary care database to conduct a matched case-control study to investigate if adult height and socioeconomic status are associated with IPF. Incident cases of IPF were identified using previously published Read Codes. General population controls were identified as a 4:1 incident density sample, matched by age, gender and general practice. Our exposures were adult height and socio-economic index as measured by Townsend Index recorded before the date of diagnosis. We used conditional logistic regression to estimate odds ratios for the associations between each exposure and IPF. Adult height was modelled as quintiles and as a continuous variable.

Results The final study population consisted of 1699 incident cases of IPF and 5339 matched general population controls. Mean age of cases was 74.6 years (Standard Deviation [SD] 9.6) and $64.2 \%$ were male. Mean height in men and women were 1.73 (SD 0.07) and 1.59 (SD 0.6) metres respectively. There was no association between adult height quintiles and IPF after adjusting for socio-economic status (see Table 1). However, when modelled as a continuous variable, we found a weak inverse association between every metre increase in adult height and IPF, after controlling for socio-economic status. (OR 0.46, 95\% CI 0.19-1.07; $\mathrm{p}=0.07$ ). There was also strong evidence of effect modification between adult height and sex $(p=0.03)$, such that the effect of increasing height quintile was stronger in women (OR $0.93,95 \%$ CI 0.87 to 0.99 ) and weaker in men (OR $0.99,95 \%$ CI 0.94 to 1.04 ). We found no association between socio-economic status and IPF (see Table 1).

Conclusions Our findings raise the possibility that early life exposures may influence the lifetime risk of developing idiopathic pulmonary fibrosis. We also demonstrated that unlike many respiratory diseases, IPF is spread evenly through all sections of society.

Abstract P152 Table 1 Odds ratios for the association between IPF, height quintile and Townsend score

\begin{tabular}{lccll}
\hline & \multicolumn{2}{l}{ Univariate analysis } & \multicolumn{2}{l}{ Multivariate analysis* } \\
\cline { 2 - 5 } & $\begin{array}{l}\text { Odds } \\
\text { ratio }\end{array}$ & $\begin{array}{l}95 \% \text { confidence } \\
\text { interval }\end{array}$ & $\begin{array}{l}\text { Odds } \\
\text { ratio }\end{array}$ & $\begin{array}{l}95 \% \text { confidence } \\
\text { interval }\end{array}$ \\
\hline $\begin{array}{l}\text { Quintile of Height } \\
1 \text { (shortest) }\end{array}$ & 1.00 & & \\
2 & 0.94 & $0.78-1.14$ & 0.94 & $0.78-1.14$ \\
3 & 0.92 & $0.74-1.15$ & 0.93 & $0.74-1.15$ \\
4 & 0.86 & $0.65-1.05$ & 0.87 & $0.65-1.06$ \\
5 (tallest) & 0.83 & $0.67-1.10$ & 0.85 & $0.68-1.11$ \\
Quintile of Townsend Score & & & \\
1 (most & 1.00 & & 1.00 & \\
disadvantaged) & & & & \\
2 & 1.02 & $0.86-1.21$ & 1.02 & $0.86-1.21$ \\
3 & 0.93 & $0.77-1.11$ & 0.92 & $0.76-1.11$ \\
4 & 1.05 & $0.86-1.27$ & 1.04 & $0.86-1.27$ \\
5 (least & 1.07 & $0.86-1.35$ & 1.07 & $0.85-1.34$ \\
disadvantaged) & & & & \\
\hline
\end{tabular}

${ }^{*}$ Adjusted for all other variables in the table

\section{P153 CLINICAL FRAILTY SCORE BUT NOT AGE IS ASSOCIATED WITH EARLY TREATMENT DISCONTINUATION WITH ANTIFIBROTIC MEDICATION IN IDIOPATHIC PULMONARY FIBROSIS}

${ }^{1} S$ Davies, ${ }^{1} \mathrm{~A}$ Holt, ${ }^{2} \mathrm{~J}$ Sutcliffe, ${ }^{2} \mathrm{~S}$ Agnew, ${ }^{1} \mathrm{D}$ Menzies, ${ }^{2} \mathrm{LG}$ Spencer. ${ }^{1} \mathrm{G}$ lan Clwyd Hospital, Betsi Cadwaladr University Health Board, Bodelwyddan, UK; ${ }^{2}$ Aintree University Hospital, Liverpool, UK

\subsection{6/thoraxjnl-2017-210983.295}

Introduction Antifibrotic medication (AFM) is indicated for the treatment of idiopathic pulmonary fibrosis (IPF), but medication related side effects can lead to early discontinuation of therapy in some patients. Factors that may predict intolerance of AFM are poorly described

Methods Retrospective data from all patients from a single District General Hospital that had received AFM for IPF between January 2014 and March 2017 were analysed. Patients were defined at four months as either tolerant or intolerant of AFM determined by either continuation of treatment, or discontinuation of treatment because of medication related side effects respectively. Fisher's exact test was used to compare age, body mass index (BMI) and Clinical Frailty Score (CFS) between the two groups. Frailty was defined as a 